\title{
Successive reversals of a discriminated preference for signaled tailshock*
}

\author{
RALPH R. MILLER, DAVID DANIEL, and ALVIN M. BERK \\ Brooklyn College of the City University of New York, Brooklyn, New York 11210
}

\begin{abstract}
Three rats received unmodifiable tailshock at random intervals in a shuttlebox. In a continuous-choice situation, Ss could choose between an auditory signal immediately preceding or immediately following the tailshock. Over repeated daily $3-\mathrm{h}$ sessions, each $\mathrm{S}$ acquired a- spatial discrimination indicating a strong preference for the signal preceding tailshock. This preference continued undiminished through two successive reversals of the position associated with signaled shock. This demonstration precludes explanations of the preference-for-signaled-shock phenomenon based upon primary reinforcement value or acquired value of the signal, position preferences, and overt modification of the aversiveness of the reinforcer through such means as postural adjustments. An explanation of recent failures to obtain the preference-for-signaled-shock effect is offered.
\end{abstract}

Rats (Badia \& Culbertson, 1972) and humans (Lanzetta \& Driscoll, 1966) are commonly believed to prefer signaled shock to unsignaled shock, even when the shock is not modifiable. The "preference-for-signaledshock (PSS) phenomenon" ordinarily refers only to cases of unmodifiable shock. Due to the use of aversive reinforcement, the PSS effect is clearly not subject to Wyckoff's (1959) conditioned stimuli explanation of the preference-for-signaled-appetitive-reinforcement phenomenon. Three alternative explanations have been suggested. Following the lead of Perkins (1955) and Prokasy (1956), Knapp, Kause, and Perkins (1959) have proposed that the signal permits the animal to emit an internal preparatory response that attenuates the aversive quality of the externally unmodifiable shock. Alternatively, applying the principles of Berlyne's (1960) theory, it has been suggested (Lanzetta \& Driscoll, 1966) that animals find receipt of any and all information about their environment reinforcing. Finally, Seligman (1971) and Badia and Culbertson (1972) have proposed that the value of a signal preceding unmodifiable shock is that the absence of the signal reduces anxiety during nonshock periods. The first and third positions are consistent with the broad-view preparatory-response concept of reinforcement suggested by Perkins (1968). The present authors believe that these three hypotheses have yet to be adequately tested in the PSS situation.

Recently, however, it has been argued (e.g., Biederman \& Furedy, 1973; Furedy \& Doob, 1972) that the PSS phenomenon does not, in fact, exist when the shock is truly unmodifiable. Specifically, Biederman and Furedy (1973) point out that most of the PSS experiments did not use fixed electrodes, thereby permitting "unauthorized" modification of shock to be

*This research was supported by NIMH Grant 19497 and a grant from the Research Foundation of the City University of New York. Reprint requests should be addressed to Ralph $R$. Miller, Department of Psychology, Brooklyn College of CUNY. Brooklyn, N.Y. 11210. achieved through changes in posture. They compared PSS using unscrambled footshock, scrambled footshock, and tailshock and found the effect to occur only in the case of unscrambled footshock. Moreover, Biederman and Furedy attribute previously reported large PSS effects, using either scrambled footshock or shock administered through fixed electrodes (e.g., Badia \& Culbertson, 1972), to the photic reinforcement value of the light signal used in those experiments. The validity of this contention appears possible but unlikely, since light is a weak reinforcer to which animals show relatively rapid habituation. Furedy and Doob (1972) further argue that the PSS effect reported by Lanzetta and Driscoll (1966) in human Ss wearing fixed electrodes was probably due to the specific wording of the questions asked the $\mathrm{Ss}$ and other demand characteristics of the experimental situation.

One positive instance of PSS worthy of special attention was executed by Perkins, Seymann, Levis, and Spencer (1966, Experiment V), who controlled for all of the confounding factors discussed above. The weakness that Biederman and Furedy (1973) find with this study is that, due primarily to electrode problems, out of 25 animals starting the experiment, only 16 finished Day 1 , 10 finished Day 2, 3 finished Day 3, and 2 finished Day 4. As no reversals were performed, possibly confounding position preferences were initially controlled for by counterbalancing. A weak preference for signal-shock was seen on Day 1 (more than $50 \%$ of the last hour in 13 out of 16 animals), but this effect vanished on Day 2. A stronger effect was seen on Days 3 and 4 (more than $95 \%$ of the last hour in all remaining animals), but there is no evidence that these few remaining animals were still counterbalanced to control for possible position preferences. Even if each counterbalanced group was still represented on Days 3 and 4 , the days on which appreciable preferences were observed, one or both groups necessarily contained but a single animal. 
The present demonstration incorporated the basic paradigm of Perkins, Seymann, Levis, and Spencer (1966, Experiment V) but, rather than increase the number of Ss over that used in the previous experiment, the present study was extended to include successive reversals to control for possible position preferences. Also, to prevent electrode problems such as removal by the $\mathrm{S}$, tail electrodes rather than ear electrodes were used. Moreover, to control for possible primary reinforcing effects of the auditory signal, the present study offered a choice between signal-shock and shock-signal rather than between signal-shock and shock only.

\section{METHOD}

\section{Subjects}

Three male Sprague-Dawley-descended rats, obtained from Carworth (New City, N.Y.) were used. They were individually housed in continuous light and were maintained on ad lib water and $10 \mathrm{~g} /$ day of powdered Purina Lab Chow. The restricted diet helped prevent the animals from outgrowing the apparatus. At the outset of the experiment. Ss 31 and 32 were approximately 80 days old and $S 34$ was aged at about 105 days.

\section{Apparatus}

Testing took place in a standard tilt-floor shuttlebox (BRS-LVE Model 146-04) equipped with a transparent drop ceiling suspended $6 \mathrm{~cm}$ above the grid floor. The ceiling contained a centered slot, running the length of the apparatus, through which the S's tail protruded. An acutely applied Plexiglas ring, taped to the tail above the ceiling, prevented the animal from retracting its tail. The electrodes, which consisted of fuserlips lubricated with a $35 \%-65 \%$ (by volume) glycerine-saline solution were acutely attached above the Plexiglas ring, approximately $1.5 \mathrm{~cm}$ apart. Counterweighted shock leads passed through a commutator system that permitted the animal rotational freedom; hence, other than being prevented from rearing, due to the low ceiling, the $S$ was quite free to locomote within the shuttlebox. Each tailshock was a 0.5 -sec constant current of $0.4 \mathrm{~mA}$ at $60 \mathrm{~Hz}$. The two compartments of the shuttlebox each measured $22.5 \times 20 \mathrm{~cm}$, were joined by a $3.7-\mathrm{cm}$-wide doorway with a $1.3-\mathrm{cm}$-high threshold, and were made discriminable by black or white walls. A random-noise generator $\left(70 \mathrm{~dB}\right.$ above $\left.0.0002 \mathrm{dynes} / \mathrm{cm}^{2}\right)$ masked ambient noises. The signal was a $10-\mathrm{sec}$ narrow-frequency tone (approximately $2,000 \mathrm{~Hz}$ ) at $76 \mathrm{~dB}$. All programming equipment was far-removed from the running room to prevent relay closures from serving as cues.

\section{Procedure}

Preference Tests. On Days 1 and 2, each S was given a 3-h adaptation and position-preference session with shock electrodes affixed and noise generator operating. Except for the omission of both signal and shock, these sessions were identical to the testing sessions which are described in detail below. All Ss preferred the black side. Consequently, two of the three Ss were assigned the nonpreferred (white) compartment as their initial signal-shock location during testing. S 32 started with the shock-signal condition in the white compartment.

Testing. Each daily session lasted $3 \mathrm{~h}$, comprising 90012 -sec periods. A random-probability generator, set for $10 \%$, was activated at the beginning of each period to determine whether an experimental presentation would occur. When the decision was affirmative, the presentation consisted of signal-tailshock or tailshock-signal, depending upon which side of the apparatus the $S$ occupied at the onset of the period. The S's position was automatically recorded at the start of each period, and these data constituted the dependent variable of the study. Once started, a signal-shock or shock-signal sequence continued to completion, regardless of the behavior of the animal. The only choice available to the animal was the order of presentation of the 10-sec signal and $0.5-\mathrm{sec}$ tailshock, since both stimuli occurred during each treatment period. All Ss started each session on the white side, regardless of the shock condition with which this compartment was associated. Approximately 70 to 110 shocks were delivered per session $($ mean $=90)$. Each $S$ was run under its original condition until a criterion was reached. Criterion was defined as 3 consecutive running days with $90 \%$ or more of all periods (shock and nonshock) begun with the animal on the signal-shock side of the shuttlebox (PSS) or, conversely, 3 consecutive running days with $90 \%$ or more of all periods begun on the shock-signal side. Upon reaching either of these criteria, the compartment formerly associated with the signal-shock condition became the location for shock-signal until the $S$ responded to the reversal by again sustaining either $90 \%$ criterion for 3 consecutive days. A second reversal was then instituted, with testing continuing until a $90 \%$ criterion was met for the third time. Criteria met immediately following reversal consistent with perseveration of the preference just met were not counted toward the next criterion to be met.

\section{RESULTS}

The results are illustrated in Fig. 1. All three Ss acquired the initial discrimination and both subsequent reversals. ${ }^{1}$ The robustness of the phenomenon is attested to by the fact that every animal met each successive signal-shock criterion without ever attaining the alternative criterion of 3 days of $90 \%$ preference for shock-signal, except immediately following a reversal after reaching a signal-shock criterion. In the face of such consistent behavior, it was felt that there was no need to extend the demonstration to a larger number of animals. Sustained criterion preferences for signaled shock were achieved by Test Session 12 (S 31), Test Session 22 (S 32), or Test Session 6 (S 34). First-reversal acquisition required 6,14 , and 10 sessions and second-reversal acquisition took 7, 16, and 15 sessions, respectively, suggesting that no savings had occurred over the successive reversals. Approach to criterion over daily sessions tended to be distinctly nonmonotonic.

Examination of shuttle responses revealed that animals averaged eight shuttles per session (four round trips) over noncriterion sessions and 4.5 shuttles per session over criterion sessions. In the former case, the shuttling was relatively uniformly distributed within sessions, with a mild clustering in the first half of the session (approximately 60\%). In the latter case, the shuttling was strongly clustered in the first half of the session $(>90 \%)$. Given the low number of shuttles per session, a continuous running measure of time spent on the signal-shock side could not differ appreciably from the present measure of location at the onset of each period. 

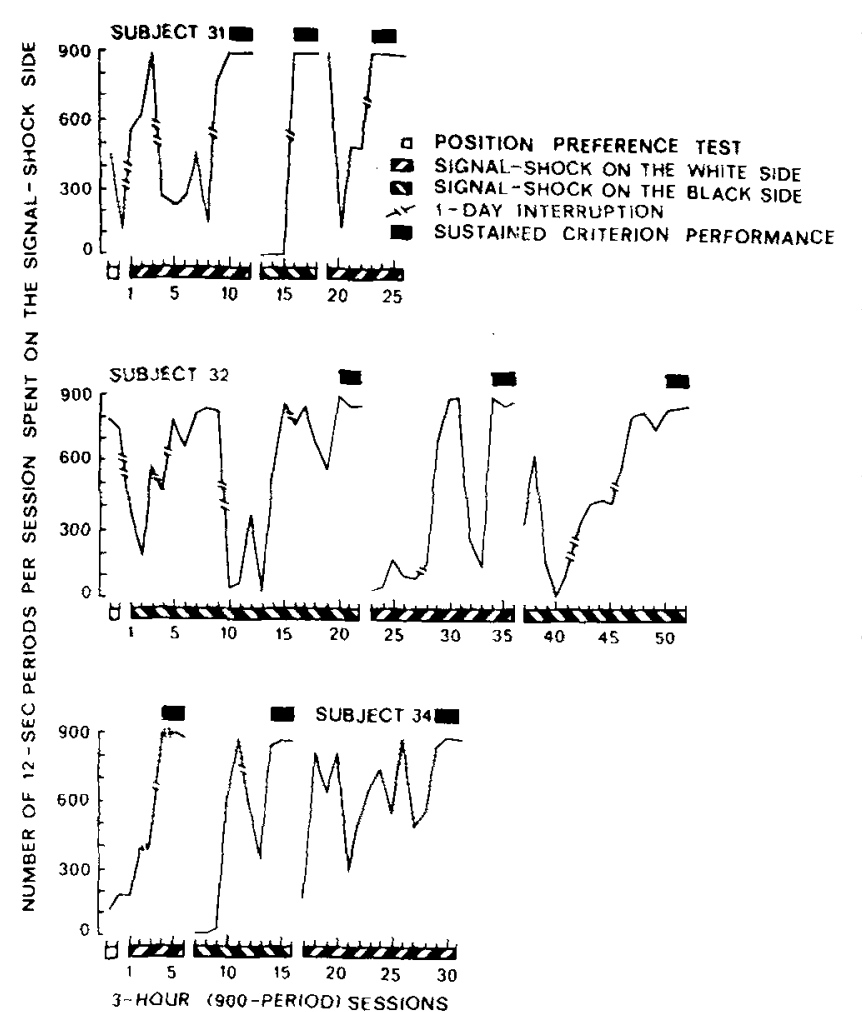

Fig. 1. Number of 12-sec periods out of 900 beginning with the $S$ in the signal-shock compartment. As there was neither signal nor shock on the preference tests, the "shock-signal side" arbitrarily has been defined to be consistent with the initial training condition (i.e., white for Ss 31 and 34 and black for S 32).

\section{DISCUSSION}

The present demonstration lends support to the validity of the PSS phenomenon while leaving open, at this time, its underlying basis. Contrary to the findings of Biederman and Furedy (1973), using a somewhat different paradigm, the effect was neither weak nor restricted to overtly modifiable shock. Of course, the possibility of internal modification still exists (Perkins, 1955). One possible reason that the present results differ from those of earlier studies, which failed to obtain a PSS effect with fixed shock electrodes (Biederman \& Furedy, 1973), is that the earlier experiment consisted of only 50 choice trials. The present study administered an average of 90 trials/day over many days (see Fig. 1). In fact, the present results are actually consistent with those of Biederman and Furedy; data from Days 1, 2, and 3 evinced littie or no PSS effect in any of the animals, indicating that, at least in the present situation, more than 270 trials are necessary for the phenomenon to appear. Of course, task differences between Biederman and Furedy and the present study render such quantitative comparisons tenuous. Biederman and Furedy (p. 382) also argue that free-choice procedures for examining the PSS phenomenon can be confounded by side effects such as the $\mathrm{Ss}^{\prime}$ freezing in response to shock. The present study obviated this criticism by the placement of all the Ss in the white compartment at the start of each session, throughout successive discrimination reversals. Freezing would therefore consistently appear as a preference for the white compartment; however, all three animals showed a strong preference for the black compartment when it was paired with the signal-shock condition.

Repeated presentations of a signal followed by shock are known to result in conditioned aversion to the signal. Consequently, we may assume, all other factors being equal, that the signal is more aversive after repeated signal-shock trials than after repeated shock-signal trials (Harsh \& Badia, 1974). In the present study, the PSS phenomenon apparently overrides any such effects of conditioning, despite the animal's opportunity to display a preference for unsignaled shock prior to reaching a criterion for PSS. However, the nonmonotonic approaches to criterion which were evident in several instances in Fig. 1 may reflect competition between the PSS effect and the acquired aversiveness of the signal.

Casual observation of the animals during criterion performance revealed that shuttling occurred appreciably more often during the signal presentations than during any other interval. Hymowitz (1973) has reported similar behavior in a PSS experiment using scrambled footshock. He suggested that the signal had become a cue for a general alarm reaction (Bolles, 1970) of which running was an inherent component in the rat. We have no basis for rejecting this view, at present, but would like to propose an alternate hypothesis. Assuming that the Ss prefer signaled shock to unsignaled shock does not necessarily mean that they are attracted to the signal per se. Perhaps, when performing at criterion, they stay in the signal-shock compartment to learn of the impending shock. However, once the signal has come on, prolonged exposure to it on any given trial provides no new information and is aversive, due to its prior association with shock (Harsh \& Badia, 1974). Consequently, the animal performs a discriminated escape from the compartment associated with signal onset, i.e., the signal-shock compartment, until such time as that compartment once again offers the possibility of new information not available in the shock-signal compartment, that time being the moment of shock offset.

\section{REFERENCES}

Badia, P., \& Culbertson, S. The relative aversiveness of signalled vs unsignalled escapable and inescapable shock. Journal of Experimental Analysis of Behavior, 1972, 17, 463-471.

Berlyne, D. E. Conflict, arousal, and curiosity. New York: McGraw-Hill, 1960.

Biederman, G. B., \& Furedy, J. J. Preference-for-signalled-shock phenomenon: Effects of shock modifiability and light reinforcement. Journal of Experimental Psychology, 1973, 100, 380-386.

Bolles, R. C. Species-specific defense reactions and avoidance learning. Psychological R eview. 1970, 77, 32-48.

Furedy, J. J., \& Doob, A. N. Signaling unmodifiable shocks: Limits on human informational cognitive control. Journal of Personality \& Social Psychology, 1972, 21, 111-115. 
Harsh, J., \& Badia, P. A concurrent assessment of the positive and negative characteristics of a signalled shock schedule. Presented at Eastern Psychological Association meeting, Philadelphia, April 1974.

Hymowitz, N. Preference for signalled ovex unsignalled response-independent electric shock. Paper presented at the meeting of the Eastern Psychological Association, Washington, D.C., May 1973 .

Knapp, R. K., Kause, R. H., \& Perkins, C. C., Jr. Immediate vs delayed shock in $T$-maze performance. Journal of Experimental Psychology, 1959, 58, 357-362.

Lanzetta, J. T., \& Driscoll, J. M. Preference for information about an uncertain but unavoidable outcome. Journal of Personality \& Social Psychology, 1966, 3, 96-102.

Perkins, C. C.. Jr. The stimulus conditions which follow learned responses. Psychological Review, 1955, 62, 41-348.

Perkins, C. C., Jr. An analysis of the concept of reinforcement. Psychological R eview, 1968, 75, 155-172.

Perkins, C. C., Jr., Seymann, R. G., Levis, D. J., \& Spencer, H. R., Jr. Factors affecting preference for signal-shock over shock-signal. Journal of Experimental Psychology, 1966, 72, 190-196.
Prokasy, W. F., Jr. The acquisition of observing responses in the absence of differential external reinforcement. Journal of Comparative \& Physiological Psychology, 1956, 49, 131-134.

Seligman, M. E. P., Maier, S. F., \& Solomon, R. L. Unpredictable and uncontrollable aversive events. In F. R. Brush (Ed.), Aversive conditioning and learning. New York: Academic Press, 1971

Wyckoff, L. B. Toward a quantitative theory of secondary reinforcement. Psychological Review, 1959, 66, 68-77.

\section{NOTE}

1. In addition to the three animals reported, four other rats were started in the study. Three were eliminated after the first day of training because they bit the bases of their tails. The fourth animal reached the initial criterion and the first reversal criterion before developing the tail-biting syndrome. Of all the animals observed, over three successive sessions, none ever exhibited a $90 \%$ preference for shock-signal except when perseverating immediately after a reversal.

(Received for publication March 28, 1974; revision received June 4,1974 .) 